\title{
4. Reducing maternal mortality in Mexico: building vertical alliances for change
}

\author{
MICHAEL D. LAYTON, BEATRIZ CAMPILLO \\ CARRETE, IRERI ABLANEDO TERRAZAS, \\ ANA MARÍA SÁNCHEZ RODRÍGUEZ
}

Maternal mortality - death resulting from pregnancy and birth - often results not only in the preventable loss of a human life, but also in family break-ups. Although it can be construed as a public health concern, it intertwines with problems like gender equality, poverty, marginalization and effective state delivery of basic services. The last two decades have seen impressive efforts at the local, national and international levels to reduce maternal mortality. The fifth Millennium Development Goal (MDG) targets reducing the maternal mortality rate by three-quarters by 2015. Although this should be an attainable target, the problem persists in the developing world, where 98 per cent of deaths occur (Keith-Brown 2005).

Mexico has an unusually high rate of maternal mortality, and those who suffer most are poor, indigenous rural peasants, many of whom do not speak Spanish. Most are in much the same situation today as they were in 1990, the MDG benchmark year. High maternal mortality rates are principally a failure of political will and attention, reflected in poor policy design and inadequate budget allocations. How can neglected communities and their advocates not only win policy commitments from the state, but turn those commitments into actual reforms, increased spending and improved governmental practices? How can citizen engagement offer a vehicle for these communities to address this social injustice?

In Mexico, civil society efforts have taken place against a background of transition to democracy. For seven decades, Mexico was governed by a single party, the Partido Revolucionario Institucional (PRI, Institutional Revolutionary Party). A gradual process of democratization began as early as 1989 when PRI lost a series of sub-national gubernatorial elections; it lost its majority in Congress in 1997, and the presidential election of 2001. One factor in PRI's electoral decline was mobilization of social groups and civic alliances united by their commitment 
to free and fair elections. But democratization 'was more a result of a decomposition of the previous order than the result of a massive opposition between state and civil society. No strong organized opposition with roots in labour or peasant movements emerged to challenge the dominant regime' (Franceschet and McDonald 2004: 17). This lack of a firm social basis for the democratic transition has shaped efforts to reduce maternal mortality.

This chapter examines a campaign by Mexican NGOs to make government take maternal mortality more seriously and provide the leadership, programmatic changes and funding necessary to reduce it. In spite of the difficulties presented by an adverse and complex environment, the campaign was largely successful in achieving its short-term goals and making progress towards the ultimate goal of reducing the maternal mortality rate. This chapter examines the impact and limitations of citizen engagement in modifying public policy. It highlights the conditions under which citizen activism can contribute to the formulation and implementation of national policies that have a positive impact on the poor, and some of the trade-offs involved in such efforts.

\section{The context of maternal mortality in Mexico}

Access to healthcare is a basic right guaranteed by the Mexican constitution, and stated in several international human rights agreements to which the Mexican government is a signatory. How well the government fulfils these obligations is a key indicator of its progress in the democratic transition.

For decades, the healthcare system in Mexico was based on three pillars: mandatory health insurance for all employees in the private and public sectors, co-financed by employers, employees and the state; private medical services, financed by the users; and medical services for the general public, those without public or private insurance. This third pillar consists of hospitals and clinics serving those who are either unemployed or working in the informal sector. In 2003, Congress enacted the legislation to expand healthcare to those excluded by the previous system. The Seguro Popular de Salud entitles beneficiaries to a series of medical services, and is financed by the federal and state governments and a needs-based contribution from the participants (Instituto Nacional de Salud Pública 2007).

Healthcare provision for the general public was originally administered by the Federal Ministry of Health, but was decentralized during the late 1980s, creating in practice thirty-two health services, one for each state (Pérez et al. 2005). This increased power and responsibility 
at the state level, viewed by many as a critical aspect of strengthening democracy, was not matched by greater accountability and transparency, placing more power and resources at the state and local levels and out of range of public scrutiny. Although Mexico has made some progress in allocating a greater share of public spending on healthcare to the poor, Scott (2004) found high levels of inequality between states in terms of health measures and funding, and a relatively low level of public spending compared to other Latin American countries.

In addition, healthcare workers' unions are a major obstacle to reforms aimed at improving the quality of health services, especially at the local level. The major unions were once an integral part of the PRI's corporatist structure, and their leaders are a holdover from the old regime, embodying the elements most resistant to change. This has led to the persistence of 'blackmail, corruption, corporatism, untouchable power groups and political concessions' (Nigenda and Ruiz 2004: 4) in the sector, undermining even the most basic changes in healthcare policy and practices. These are particularly acute in the southern states of Guerrero, Chiapas and Oaxaca, where both maternal mortality rates and poverty levels are highest (Paqueo and González 2003).

The Ministry of Health states that the national maternal mortality rate has steadily decreased in the past fifteen years, from 89 deaths per 100,000 live births in 1990, to 83.2 in 1995, 72.6 in 2000 and 63.3 in 2005 (Secretaría de Salud 2005). These national-level statistics hide vast inequalities between states, and state-level indicators demonstrate that women who live in conditions of poverty and marginalization have the highest maternal mortality rates (González 2005). Hence, the 2005 maternal mortality rate for Guerrero stood at 128 deaths per 100,000, more than double the national level (ibid.), and maternal mortality is three times higher in indigenous communities than in the rest of the country (Damián 2004).

Ninety-eight per cent of indigenous municipalities in Mexico are characterized by high levels of outmigration, a subsistence economy, limited communication, poor transportation access, a dispersed population, and environmental degradation (Secretaría de Desarrollo Social 2007). The interplay of these factors impedes women's access to sanitary living conditions and basic health information and care, much less emergency medical interventions, one of the key factors in reducing maternal mortality. Shortcomings regarding access to health services are not the only problem. The precarious conditions in which indigenous people live also increase the risk of contracting infections that could complicate a pregnancy: for example, 40 per cent of their housing has 